\title{
Backbone Dynamics of Detergent-Solubilized Alamethicin from Amide Hydrogen Exchange Measurements ${ }^{\dagger}$
}

\author{
Adelinda Yee, Blair Szymczyna, and Joe D. O’Neil* \\ Department of Chemistry, University of Manitoba, Winnipeg, Manitoba R3T 2N2, Canada \\ Received December 16, 1998; Revised Manuscript Received March 11, 1999
}

\begin{abstract}
Alamethicin is a 20 amino acid antibiotic peptide produced by the soil fungus Trichoderma viride. The peptide inserts into bacterial membranes and self-associates to form ion channels, but the details of this process are unknown. Residue-specific acid- and base-catalyzed exchange data were obtained for 16 of 18 backbone amides of alamethicin dissolved in sodium dodecyl sulfate micelles using highresolution 2-dimensional heteronuclear nuclear magnetic resonance spectroscopy. To facilitate interpretation of the exchange data, we synthesized $N$-acetyl- $\alpha$-aminoisobutyric acid- $N^{\prime}$-methyl and $N$-acetyl-alanine$N^{\prime}$-methyl and measured the $\mathrm{pD}$ dependence of their hydrogen-deuterium exchange rates to determine the sequence-dependent inductive and steric effects of the $\alpha$-aminoisobutyric acid residue. Intramolecular $\mathrm{H}$-bonding in alamethicin was monitored through the exchange parameters $k_{\min }$ (minimum exchange rate) which indicate that the backbone is significantly more stable than the backbones of alanine-based helical peptides. Rapid exchange at Gly-11 suggests a highly local conformational flexibility in the middle of the peptide. Interactions with the detergent micelle were revealed by the exchange parameters $\mathrm{pD}_{\min }(\mathrm{pD}$ of minimum exchange) which suggest that the $\mathrm{N}$-terminus of alamethicin interacts more strongly with the detergent micelle than does the $\mathrm{C}$-terminus. A periodicity in $\mathrm{pD}_{\min }$ difference data reveals that one surface of the helix interacts more strongly with the micelle. The surface consists of residues 1, 5, 9, 13, 16, and 20. The opposite face of the helix contains several polar residues (two glutamines and a glycine), suggesting that, on average, this face of the helix is directed toward the solvent. These results serve as a model for the interaction of the peptide with membranes containing anionic lipid. In combination with published molecular dynamics simulations [Gibbs et al. (1997) Biophys. J. 72, 2490-2495], the present results also offer insight into the mechanisms of hydrogen-deuterium exchange in helical peptides.
\end{abstract}

Progress in elucidating the structures, dynamics, and folding pathways of intrinsic membrane proteins has been slow because membrane proteins are usually insoluble in water, they do not crystallize easily, and they are difficult to obtain in large quantities. Natural and synthetic peptides have proven to be useful for modeling the interactions between proteins and lipid bilayers and have provided insight into peptide secondary structure formation, the insertion of helices into bilayers, and the association of transmembrane helices within membranes (1). One of the most intensely investigated model peptides is alamethicin, a 20 amino acid antibiotic produced by the soil fungus $T$. viride. The antibiotic activity of the peptide is thought to occur by virtue of its ability to breach the integrity of bacterial membranes, although the mechanism by which this occurs is not completely understood $(2-4)$. X-ray diffraction studies show that, at low concentrations, alamethicin adsorbs onto the surface of a membrane deforming it (5). At higher concentrations the peptide inserts across the bilayer and selfassociates to form ion channels which have been investigated structurally by neutron in-plane scattering $(6,7)$ and functionally by single-channel, patch-clamp conductance record-

\footnotetext{
$\dagger$ The financial assistance of the Natural Sciences and Engineering Research Council and the University of Manitoba is gratefully acknowledged.

* To whom correspondence may be addressed.
}

ings (8). The opening and closing of the pores can be controlled by the application of a potential difference across the bilayer which has made alamethicin a valuable model for the voltage-gated ions channels of nerve and muscle (3).

Alamethicin structure and dynamics have been studied in a variety of solvents and with the use of molecular dynamics simulations. A high-resolution X-ray diffraction structure was determined by Fox and Richards (9) on crystals grown in 90:10 acetonitrile - methanol. The crystals hold three slightly different bent helices, containing predominantly $\alpha$-helical $\mathrm{H}$-bonding with different numbers of $3_{10}$ interactions. In both methanol (10-12) and aqueous detergent solutions (13) only enough $\mathrm{NOE}^{1}$ and $\mathrm{J}$-coupling data have been obtained to

\footnotetext{
${ }^{1}$ Abbreviations: Aib, $\alpha$-aminoisobutyric acid; DSS, disodium 2,2dimethyl-2-silapentane-5-sulfonate; EDAC, 1-ethyl-3-(3-dimethylaminopropyl)carbodiimide $\cdot \mathrm{HCl}$; $\mathrm{HMQC}$, heteronuclear multiple-quantum coherence; $\mathrm{H}_{\mathrm{N}}(\mathrm{L})$, amide proton left of the sidechain; $\mathrm{H}_{\mathrm{N}}(\mathrm{R})$, amide proton right of the side chain; HSQC, heteronuclear single-quantum coherence; $k_{\mathrm{A}}$, acid-catalyzed exchange rate; $k_{\mathrm{B}}$, base-catalyzed exchange rate; $k_{\mathrm{cl}}$, conformational closing rate constant; $K_{\mathrm{D}}$, molar ionization constant of $\mathrm{D}_{2} \mathrm{O} ; k_{\mathrm{D}_{2} \mathrm{O}}$, water-catalyzed hydrogen exchange rate constant; $k_{\min }$, rate of hydrogen exchange at the $\mathrm{pD}_{\min } ; K_{\mathrm{op}}$, conformational opening equilibrium constant; $k_{\mathrm{op}}$, conformational opening rate constant; $k_{\mathrm{obs}}$, measured hydrogen exchange rate; $\mathrm{k}_{\mathrm{rc}}$, calculated random coil hydrogen exchange rate; Me, methyl; NMR, nuclear magnetic resonance; NOE, nuclear Overhauser enhancement; $\mathrm{pD}_{\text {min: }} \mathrm{pD}$ of minimum exchange; $\mathrm{pD}_{\text {read }}, \mathrm{pH}$ meter reading in $\mathrm{D}_{2} \mathrm{O}$; PDLA, poly-D,L-alanine; PF, protection factor; SDS, sodium dodecyl sulphate; SDS-D 25 , perdeuterated SDS.
} 
loosely fold the peptide into a helical conformation, and this has been interpreted to suggest that the peptide backbone is highly flexible in these solvents. Molecular dynamics calculations $(14,15)$ and nitroxide enhancement of ${ }^{1} \mathrm{H}$ NMR relaxation rates (16) also suggested significant dynamic flexibility in the peptide backbone. In contrast, residuespecific NMR relaxation studies, which monitor backbone fluctuations on the picosecond time scale, $(17,18)$ suggested that in alamethicin a stable secondary structure is formed throughout its length both in methanol and in aqueous detergent solution. In methanol (a mild helix-promoting solvent; ref 19), indications of a stable helix come from the observations of a possible helix macrodipole effect on amide proton chemical shifts (12), from the small temperature dependence of the amide ${ }^{1} \mathrm{H}$ (12) and carbonyl ${ }^{13} \mathrm{C}(20)$ chemical shifts, and from backbone amide hydrogen exchange measurements (21).

Amide hydrogen exchange measurements, obtained with the use of high-resolution NMR spectroscopy, are one of the few techniques which can provide information about protein dynamics on the millisecond to nanosecond time scale at virtually atomic-scale resolution $(22,23)$. Measurements of backbone amide hydrogen exchange rates provide sitespecific information about fluctuations in backbone conformation usually considered to be hydrogen bond breaking events (24). Dempsey and Handcock (25) measured amide hydrogen exchange rates of lipid vesicle-associated alamethicin to obtain information about the dynamics of the peptide in a lipid environment. Because of the limited solubility of alamethicin in water and the slow tumbling of the vesicleassociated peptide which precluded measurement of its NMR spectrum, exchange trapping experiments were used to obtain the exchange data. Exchange protection factors were calculated at a single $\mathrm{pH}$ value which has the limitation that shifts in $\mathrm{pH}_{\min }$ can lead to erroneous exchange protection factors. Interestingly, the data provided valuable and detailed information about the stabilities of the hydrogen bonds of the molecule dissolved in water, a state which has been little studied. Hydrogen exchange from the membrane-associated state yielded an amide exchange protection profile that is significantly different from that measured in the aqueous (25) and methanol-solubilized states (21).

Detailed information about the dynamics of alamethicin is necessary for a full understanding of its biological and structural properties. For example, flexibility in the peptide backbone could contribute to the mechanism of insertion into membranes, the formation and stability of pores (26), channel noise, and the nature of the channel lumen by changing the orientation of backbone and side-chain residues in the lumen (15). To determine residue-specific backbone dynamics on alamethicin dissolved in aqueous detergent micelles, we carried out hydrogen exchange measurements on ${ }^{15} \mathrm{~N}$-labeled peptide using 2D heteronuclear NMR spectroscopy. The principal advantage to measuring exchange from SDS micelles compared to lipid vesicles is that, owing to the small size of the detergent-peptide complex, the full $\mathrm{pH}$ dependence of exchange can be measured directly by NMR spectroscopy. As the effects of micelles on exchange have been studied systematically (27), those results can be used in the interpretation of peptide exchange data. The present results reveal the hydrogen bond stabilities of alamethicin dissolved in aqueous detergent as well as information about the interactions between the peptide and the micelle surface. The latter provide a model for the interaction of the peptide with anionic lipid.

\section{MATERIALS}

${ }^{15} \mathrm{~N}$-labeled and unlabeled alamethicin were prepared and purified as described in ref $11 .{ }^{15} \mathrm{NH}_{4} \mathrm{Cl}\left(99.5\right.$ atom $\left.\%{ }^{15} \mathrm{~N}\right)$ from Isotec Inc. (Miamisburg, $\mathrm{OH}$ ) was used as external reference for ${ }^{15} \mathrm{~N}$ NMR spectra. ${ }^{15} \mathrm{NH}_{4} \mathrm{Cl}(2.9 \mathrm{M})$ in $1 \mathrm{M}$ $\mathrm{HCl}$ resonates at $24.93 \mathrm{ppm}$ relative to $\mathrm{NH}_{3}(\mathrm{l})$ (28). Sodium dodecyl- $\mathrm{D}_{25}$ sulfate $\left(98.6\right.$ atom $\left.\%{ }^{2} \mathrm{H}\right)$ was from Cambridge Isotope Laboratories (Anover, MA). Standard buffer solutions (Fisher Scientific Co., Fairlawn, NJ) were used to calibrate the $\mathrm{pH}$ meter. Citric acid, trisodium salt dihydrate (Sigma Chemical Co., St. Louis, MO), and succinic anhydride (Eastman Kodak Co., Rochester, NY) were used as buffers in the measurements of hydrogen exchange of the model dipeptides. $N$-Acetylalanine, $\alpha$-aminoisobutyric acid, and 1-ethyl-3-(3-dimethylaminopropyl)carbodiimide $\cdot \mathrm{HCl}$ (EDAC) were from Sigma Chemical Co., and acetic anhydride was from Fisher Scientific Co. Methylamine $\cdot \mathrm{HCl}$ was from ICN Biomedicals Inc., Aurora, $\mathrm{OH}$.

\section{METHODS}

Synthesis and Purification of N-Acetyl Amino Acid N'Methyl Amides. $N$-acetyl $\alpha$-aminoisobutyric acid was synthesized from $\alpha$-aminoisobutyric acid and acetic anhydride as described in ref 29. Acetylation was confirmed with the use of ninhydrin, and the product was purified using reversephase HPLC (11) with pure water as eluant. The amidation reactions were done by reacting $N$-acetyl $\alpha$-aminoisobutyric acid or $N$-acetyl alanine with methylamine; amide formation was promoted by the water-soluble carbodiimide, EDAC (29). The reaction mixtures were left to react overnight and were then purified by reverse-phase HPLC. ${ }^{1} \mathrm{H}$ NMR spectroscopy confirmed the identity of the $N$-acetyl amino acid $N^{\prime}$-methyl amides.

Hydrogen Exchange and NMR Spectroscopy. All NMR experiments were done on a Bruker AMX500 NMR spectrometer using a $5 \mathrm{~mm}$ inverse broadband probehead with the inner coil tuned to ${ }^{1} \mathrm{H}$ and ${ }^{2} \mathrm{H}$ (lock) and the outer coil tuned to ${ }^{15} \mathrm{~N}$. Details of the acquisition and processing parameters are given in the appropriate figure legends. Assignments of the ${ }^{1} \mathrm{H}$ and ${ }^{15} \mathrm{~N}$ NMR resonances of alamethicin dissolved in aqueous detergent solution were described earlier (18).

For the measurement of HD exchange of the $\mathrm{N}$-acetyl amino acid $N^{\prime}$-methyl amides, the procedure described in ref 30 was followed. Concentrated solutions of the $\mathrm{N}$-acetyl amino acid $N^{\prime}$-methyl amides were made by dissolving a weighed amount of amide in $1 \mathrm{~mL}$ of a $\mathrm{H}_{2} \mathrm{O}$ solution containing $50 \mathrm{mM}$ buffer and $0.5 \mathrm{M} \mathrm{KCl}$. The buffers were either succinate, for $\mathrm{pH} 4-6.5$, or citrate, for $\mathrm{pH} 4$ and below. Solutions $(0.8 \mathrm{~mL})$ containing the same buffer and salt concentrations as the concentrated amide solution but dissolved in $\mathrm{D}_{2} \mathrm{O}$ were used to dilute $0.1 \mathrm{~mL}$ of the amide solution at $5{ }^{\circ} \mathrm{C}$. After the solutions were mixed a series of $1 \mathrm{D}{ }^{1} \mathrm{H}$ NMR spectra were acquired at various times at $5{ }^{\circ} \mathrm{C}$. The amide proton intensities were integrated. In all exchange experiments the $\mathrm{pH}$ values were measured at room temperature $\left(22^{\circ} \mathrm{C}\right)$ after exchange was completed. The $\mathrm{pH}$ meter reading in $\mathrm{D}_{2} \mathrm{O}\left(\mathrm{pD}_{\text {read }}\right.$ ) was corrected using the following 
relationship:

$$
\mathrm{pD}_{\text {corr }}=\mathrm{pD}_{\text {read }}+0.4
$$

(31). The $\mathrm{p} K_{\mathrm{a}}$ values of citrate and succinate at $20{ }^{\circ} \mathrm{C}$ are higher by 0.06 units compared to those at $5{ }^{\circ} \mathrm{C}(30,32)$. Since the experiments were done at $5{ }^{\circ} \mathrm{C}$ and the $\mathrm{pH}$ was read at $20{ }^{\circ} \mathrm{C}$, the $\mathrm{pH}$ at $5{ }^{\circ} \mathrm{C}$ was calculated using the following relationship:

$$
\mathrm{pH}^{5^{\circ} \mathrm{C}}=\mathrm{pH}^{20^{\circ} \mathrm{C}}-\Delta \mathrm{p} K_{\mathrm{a}} / 2
$$

For the HD exchange experiments on alamethicin, a solution containing $150 \mathrm{mM} \mathrm{SDS}-\mathrm{D}_{25}$ and $20 \mathrm{mM} \mathrm{Na}_{2} \mathrm{HPO}_{4}$ solution in $\mathrm{D}_{2} \mathrm{O}$, the $\mathrm{pH}$ of which had been adjusted, was used to dilute a solution of alamethicin dissolved in $\mathrm{H}_{2} \mathrm{O}$ containing the same SDS and buffer concentrations. Several HMQC spectra $(33,34)$ were acquired at different times following the mixing at $27{ }^{\circ} \mathrm{C}$. Low-resolution HMQC spectra took 20 min to acquire, and high-resolution HMQC and HSQC (35) spectra were acquired over 5.5 h. For wellresolved cross peaks the cross-peak volumes were integrated. In the low-resolution spectra, where two cross peaks were not completely resolved, the combined cross peaks were integrated and peaks from $\mathrm{F}_{1}$ slices were also analyzed.

Data Analysis. The NMR peak integrals $(a)$ at each time $(t)$ were fit to a three-parameter equation using the software Passage to determine the exchange rate $\left(k_{\mathrm{obs}}\right)$ at each $\mathrm{pH}$

$$
a=a_{\mathrm{o}} \exp \left(-k_{\mathrm{obs}} t\right)+b
$$

The baseline value $(b)$ originates in the $\mathrm{H}_{2} \mathrm{O}$ present after dilution of the sample. Since the exchange experiments for alamethicin in SDS solution were conducted at $27{ }^{\circ} \mathrm{C}$, the predicted exchange rates $\left(k_{\mathrm{rc}}\right)$ at $20^{\circ} \mathrm{C}$ were extrapolated to $27{ }^{\circ} \mathrm{C}$ to allow for comparison with experimental $k_{\mathrm{obs}}$ using the equation and data from (30):

$$
k_{\mathrm{rc}}(T)=k_{\mathrm{rc}}(293) \exp \left[-E_{\mathrm{a}}(1 / T-1 / 293) / R\right]
$$

where $E_{\mathrm{a}}$ is the activation energy which is 14 and $17 \mathrm{kcal} /$ mol for $k_{\mathrm{A}}$ and $k_{\mathrm{B}}$, respectively, and $R$ is the universal gas constant.

The $\mathrm{pH}_{\text {corr }}$ values were plotted versus $k_{\mathrm{obs}}$, and these were fit to a two-parameter equation using the software $\mathrm{Ka}$ leidograph:

$$
k_{\mathrm{obs}}=k_{\mathrm{A}} 10^{-\mathrm{pD}}+k_{\mathrm{B}} 10^{\left(\mathrm{pD}-\mathrm{p} K_{\mathrm{D}}\right)}
$$

where $k_{\mathrm{A}}$ is the acid-catalyzed exchange rate constant, $k_{\mathrm{B}}$ is the base-catalyzed exchange rate constant, $\mathrm{pD}$ is the $\mathrm{pD}_{\text {corr }}$, and $K_{\mathrm{D}}$ is the molar ionization constant of $\mathrm{D}_{2} \mathrm{O}$ which is $10^{-15.65}$ at $5^{\circ} \mathrm{C}, 10^{-15.05}$ at $20^{\circ} \mathrm{C}$, and $10^{-14.801}$ at $27^{\circ} \mathrm{C}(30$, 32). Hydrogen exchange catalyzed by water can be significant especially near the $\mathrm{pD}_{\min }$ for polar amino acids $(30)$. However, because of a paucity of data near the $\mathrm{pD}_{\min }$ for most of our experiments, we did not include a term $k_{\mathrm{D}_{2} \mathrm{O}}$ for the water-catalyzed exchange rate constant. This has little effect on the determination of $k_{\mathrm{A}}$ and $k_{\mathrm{B}}$, especially since most of the residues in alamethicin are nonpolar. In the fitting procedure, the observed data were weighted by the reciprocal of their magnitude so as not to favor points far from the $\mathrm{pD}_{\min }(24,36)$. The exchange measurements on $\mathrm{N}$-acetyl-

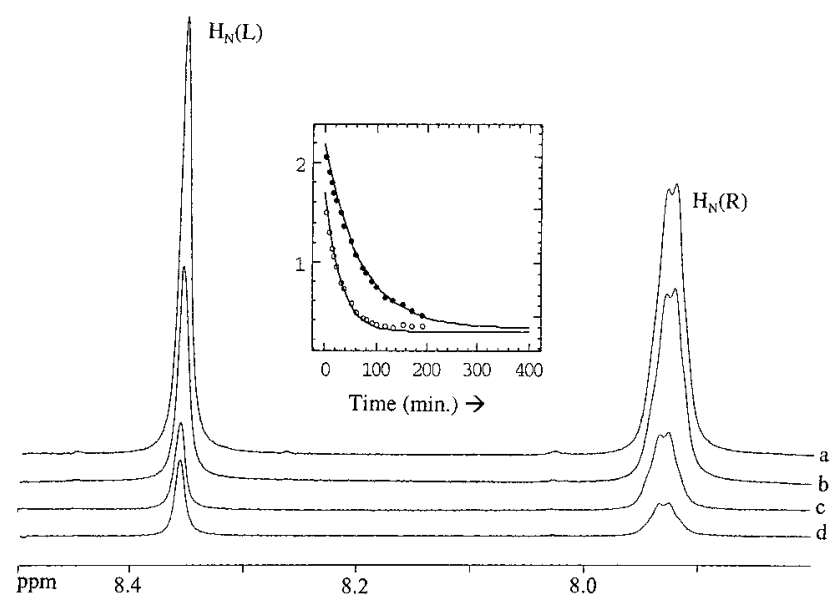

FIGURE 1: The amide regions of representative $500 \mathrm{MHz}{ }^{1} \mathrm{H}$ NMR spectra of approximately $44 \mathrm{mM} N$-acetyl-Aib- $N^{\prime}-\mathrm{Me}$ in $50 \mathrm{mM}$ succinate, $0.5 \mathrm{M} \mathrm{KCl}, 87.5 \% \mathrm{D}_{2} \mathrm{O}$, and $\mathrm{pD}_{\text {corr }} 5.2$ at (a) $6 \mathrm{~min}$, (b) $35 \mathrm{~min}$, (c) $135 \mathrm{~min}$, and (d) $1034 \mathrm{~min}$ after dissolution at $5{ }^{\circ} \mathrm{C}$. The chemical shift reference is DSS $(0 \mathrm{ppm})$. All spectra are the average of 64 scans obtained with $1.5 \mathrm{~s}$ of presaturation of the water resonance, a spectral width of $6024 \mathrm{~Hz}$, an acquisition time of 1.36 $\mathrm{s}$, and processing with $1 \mathrm{~Hz}$ line broadening. Inset: Nonlinear leastsquares fits of the exponential $\mathrm{HD}$ decays of the $\mathrm{H}_{\mathrm{N}}$ resonances of $N$-acetyl-Aib- $N^{\prime}$-Me: filled circles $(\bullet), \mathrm{H}_{\mathrm{N}}(\mathrm{R})$; open circles $(\mathrm{O})$, $\mathrm{H}_{\mathrm{N}}(\mathrm{L})$. The right $(\mathrm{R})$ and left $(\mathrm{L})$ amides, $\mathrm{H}_{\mathrm{N}}(\mathrm{R})$ and $\mathrm{H}_{\mathrm{N}}(\mathrm{L})$, are as defined in ref 37.

Aib- $N^{\prime}$-Me were used to calculate the sequence-dependent steric and inductive effects on the amides to the left and right of the Aib methyl side chains as described by Bai et al. (30). However, the measured $k_{\text {obs }}$ of the $\mathrm{H}_{\mathrm{N}}(\mathrm{L})$ of $N$-acetyl-Aib$N^{\prime}$-Me was used as $k_{\text {rc }}$ for Aib 1. The $k_{\text {rc }}$ for Phol 20 was calculated with the $\mathrm{C}$ terminus as a neutral carboxylic acid. The validity of this is discussed below.

\section{RESULTS}

$H_{N}$ Exchange Rates of $N$-Acetyl-Aib-N'-Me. Backbone amide hydrogen exchange rates in proteins must be corrected for sequence-dependent inductive and steric effects. Molday et al. (37) and Bai et al. (30) measured these effects for the 19 common L-amino acids and glycine using $N$-acetyl-amino acid- $N^{\prime}$-Me dipeptides dissolved in water. Dempsey (21) measured these effects for the Aib residue in $\mathrm{N}$-acetyl-LysAib- $N^{\prime}$-Me dissolved in deuteriomethanol. Because of the importance of carefully measured sequence-dependent effects for the proper interpretation of protein hydrogen exchange and the additional difficulties associated with $\mathrm{pH}$ measurement in methanol (38), we synthesized an Aib-containing molecule similarly to the syntheses by Bai et al. (30) and measured its amide hydrogen exchange rates under conditions identical to those described in ref 30 . As a control, we also synthesized $N$-acetyl-Ala- $N^{\prime}$-Me and measured its amide exchange rates. Figure 1 shows the amide regions of representative ${ }^{1} \mathrm{H}$ NMR spectra of $N$-acetyl-Aib- $N$-Me dissolved in $\mathrm{D}_{2} \mathrm{O}$ at different $\mathrm{HD}$ exchange times at $5{ }^{\circ} \mathrm{C}$ and $\mathrm{pD}_{\text {corr }}$ 5.2. The inset shows sample plots of integrated peak areas versus time and the nonlinear least-squares fits of the data to monoexponential decays.

Figure 2 shows the measured $\mathrm{pD}$ dependence of $\mathrm{HD}$ exchange for the $\mathrm{H}_{N}(\mathrm{~L})$ and $\mathrm{H}_{\mathrm{N}}(\mathrm{R})$ of the Aib and Ala dipeptides. The curves through the Aib data are nonlinear least-squares fits weighted as described in the Methods section. The curves through the Ala data were calculated 

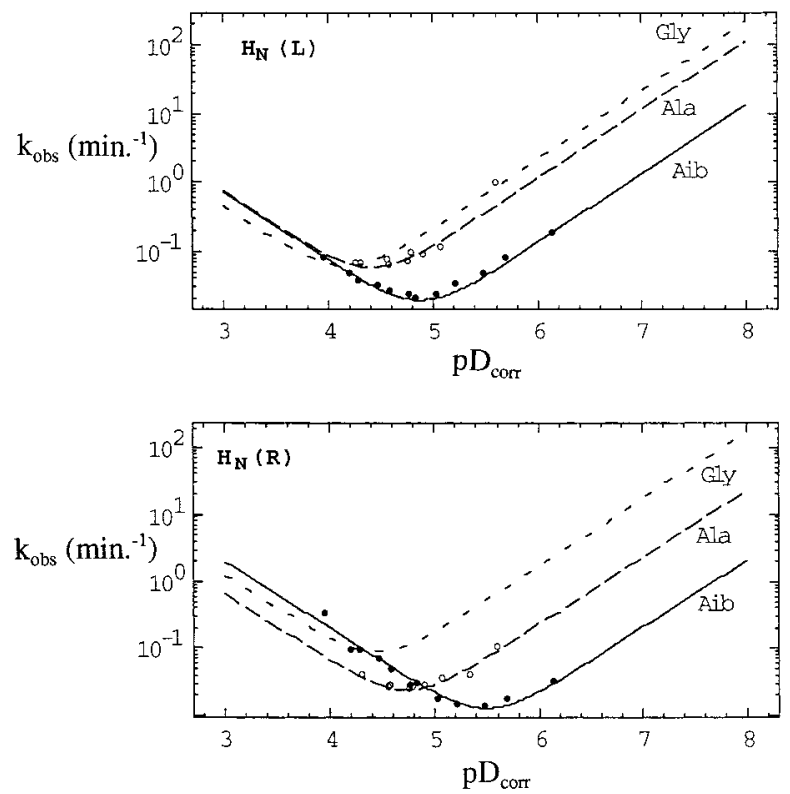

FIGURE 2: The dependence of the HD exchange rates on $\mathrm{pD}_{\text {corr }}$ of $N$-acetyl-Aib- $N$-Me (O) and $N$-aetyl-Ala- $N N^{\prime}$-Me (O). The best fits of the Aib peptide data to eq 5 are indicated by the solid lines. The dashed lines were calculated from the data of Bai et al. (30) for $N$-acetyl-Ala- $N$-Me and $N$-acetyl-Gly- $N^{\prime}$-Me.

Table 1: Calculated HD Exchange Parameters for $N$-Acetyl-Aib- $N^{\prime}$-Me at $278 \mathrm{~K}$ in $0.5 \mathrm{M} \mathrm{KCl}$

\begin{tabular}{ccccc}
\hline & $\begin{array}{c}\log k_{\mathrm{A}} \\
\left(\mathrm{M}^{-1} \min ^{-1}\right)\end{array}$ & $\begin{array}{c}\log k_{\mathrm{B}} \\
\left(\mathrm{M}^{-1} \min ^{-1}\right)\end{array}$ & $\begin{array}{c}k_{\min } \\
\left(\min ^{-1}\right)\end{array}$ & $\mathrm{pD}_{\min }$ \\
\hline (L) & 2.86 & 8.77 & $1.96 \times 10^{-2}$ & 4.87 \\
(R) & 3.30 & 7.97 & $1.29 \times 10^{-2}$ & 5.49 \\
\hline
\end{tabular}

using the exchange parameters reported by Bai et al. (30) and indicate excellent agreement between our measurements of base- $\left(k_{\mathrm{b}}\right)$ and acid-catalyzed $\left(k_{\mathrm{a}}\right)$ exchange rates, the $\mathrm{pD}$ of minimum exchange $\left(\mathrm{pD}_{\min }\right)$, and the rate of exchange at the $\mathrm{pD}_{\min }\left(k_{\min }\right)$. The curve showing the $\mathrm{pD}$ dependence of the Gly dipeptide in Figure 2 was derived from the results reported in ref 30 . The shifts to higher $\mathrm{pD}$ for the Ala dipeptide as compared to Gly, particularly for the $\mathrm{H}_{N}(R)$, are due to electron donation by the $\alpha$-methyl substituent which increases the basisity of the amide thereby increasing the acid-catalyzed exchange rate and decreasing the basecatalyzed exchange rate. The effect of two $\alpha$-methyls in Aib is to shift further the $\mathrm{pD}$ dependence of amide exchange to higher $\mathrm{pD}$. The downward shift of the Ala dipeptide curves compared to those for the Gly dipeptide are due to a steric effect of the $\alpha$-methyl. Steric blocking is larger for the $\mathrm{L}$ than for the $\mathrm{R}$ peptide $\mathrm{H}_{\mathrm{N}}$ as shown by Bai et al. (30). Our data also show that additional steric hindrance to hydrogen exchange is conferred by the second methyl in Aib compared to Ala.

The calculated base- and acid-catalyzed exchange rates, the $\mathrm{pD}_{\min }$, and $k_{\min }$ for the Aib dipeptide at $5{ }^{\circ} \mathrm{C}$ are listed in Table 1. If the values reported in ref 21 for $\mathrm{N}$-acetyl-LysAib- $N$-Me dissolved in methanol at $20^{\circ} \mathrm{C}$ are corrected for the temperature difference between our experiments (see Methods), the $k_{\min }$ of the L-amide of Aib is about 29-fold greater in water. The increased exchange rate is due partly to the higher catalyst concentrations in water

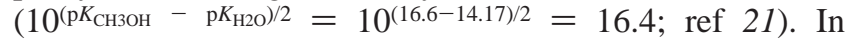
addition, $N$-acetyl-Lys-Aib- $N^{\prime}-\mathrm{Me}$ has an amino acid $\mathrm{N}$ - terminal to the Aib not found in our dipeptide. Model compound studies show that this will slow exchange by a factor of about 2.5. For example, the addition of an Ala to $\mathrm{N}$-methyl acetamide slowed exchange at the $\mathrm{pH}_{\min }$ by 2.3fold (37), and there is a 2.8-fold difference between the $k_{\min }$ for $N$-Ac-Ala- $N^{\prime}$-Me (L) and $N$-Ac-Ala-Ala-Ala- $N$-Me (30). In summary, the measured $k_{\min }$ values for the different $\mathrm{Aib}$ model compounds dissolved in methanol (21) and water (Table 1) are in excellent agreement.

The difference in uncorrected $\mathrm{pD}_{\text {min }}$ for the $\mathrm{H}_{\mathrm{N}}(\mathrm{R})$ of $\mathrm{Aib}$ in $N$-acetyl-Lys-Aib- $N^{\prime}$-Me dissolved in deuteriomethanol (21) and $N$-acetyl-Aib- $N^{\prime}$-Me dissolved in deuterated water is 0.86 units. Most of this difference is accounted for by the additional peptide unit in the former compound. For example, addition of a peptide bond to $N$-methyl acetamide lowers the $\mathrm{pD}_{\min }$ by 0.76 units (37), and the additional peptide bonds in $N$-Ac-Ala-Ala-Ala- $N^{\prime}$-Me compared to $N$-Ac-Ala- $N N^{\prime}$-Me withdraw electrons and lower the $\mathrm{pD}_{\min }$ by 0.9 units $(30)$. However, the Lys side chain in $N$-acetyl-Lys-Aib- $N$-Me would be expected to suppress acid catalysis, enhance base catalysis, and shift the $\mathrm{pD}_{\min }$ to lower $\mathrm{pD}$ by a further $\sim 0.4$ units (30). This is the minimum shift expected since the exchange of $N$-acetyl-Lys-Aib- $N^{\prime}$-Me was measured in the absence of salt, whereas the measurements of Bai et al. (30) were done in $0.5 \mathrm{M} \mathrm{KCl}$ which would partially screen the positive charge on the Lys side chain. On the basis of these considerations, the $\mathrm{pD}_{\min }$ values measured for the model compounds in methanol (21) occur at $\mathrm{pD}$ values which are higher than expected, perhaps by as much as $0.3-0.4 \mathrm{pD}$ units. This suggests exercising caution when comparing the absolute $\mathrm{pD}_{\min }$ values measured for alamethicin dissolved in the two solvent systems.

Intrinsic $H_{N}$ Exchange Rates in Alamethicin. Ideally, determination of the effects of secondary structure on the rates of backbone amide exchange in a peptide requires a measurement of the rates of HD exchange in an unfolded molecule. The high helix propensity of Aib residues has been noted by others (39), and this makes unfolding of alamethicin a difficult task (20). An alternative is to compare the measured rates of exchange to those predicted for a completely unfolded peptide using the rates of exchange for poly-D,L-alanine corrected for sequence effects. The predicted $k_{\mathrm{A}}, k_{\mathrm{B}}, \mathrm{pH}_{\min }$, and $k_{\min }$ for an unstructured alamethicin molecule dissolved in water at $27{ }^{\circ} \mathrm{C}$ are listed in Table 2 . These values were calculated from the $\log k_{\mathrm{A}}(1.62), \log k_{\mathrm{B}}$ (10.05), and $\log k_{\mathrm{D}_{2} \mathrm{O}}(-1.5)$ values adjusted to $27^{\circ} \mathrm{C}$ for poly-D,L-alanine and the amino acid side-chain correction factors published in ref 30. Correction factors for the Aib residues to the right and left of the exchanging amide were determined by subtracting the $\log \left(k_{\mathrm{ex}}\right)$ measured for $N$-acetylAla- $N^{\prime}$-Me from that measured for $N$-acetyl-Aib- $N^{\prime}$-Me. The $k_{\mathrm{A}}{ }^{\mathrm{rc}}$ and $k_{\mathrm{B}}{ }^{\mathrm{rc}}$ of Aib 1 were calculated relative to the measured $k_{\mathrm{A}}$ and $k_{\mathrm{B}}$ of the $\mathrm{H}_{\mathrm{N}}(\mathrm{L})$ of $N$-acetyl-Aib- $N^{\prime}$-Me rather than relative to PDLA. There is a 2.4-fold difference in the rates of exchange between $N$-Ac-Ala- $N^{\prime}$-Me (R) and PDLA (30). The $k_{\mathrm{A}}{ }^{\text {rc }}$ and $k_{\mathrm{B}}{ }^{\text {rc }}$ for the C-terminal phenylalaninol amide were calculated using the correction factors for a neutral carboxyl terminus (30). An alternative is to use the $H_{N}(R)$ of $N$-Ac-Ala- $N^{\prime}-\mathrm{MA}$. This calculation enhances $k_{\mathrm{A}}{ }^{\text {rc }}$ by about 100 -fold, reduces $k_{\mathrm{B}}{ }^{\text {rc }}$ by about 10 -fold, increases $\mathrm{pD}_{\min }{ }^{\text {rc }}$ to 4.27 , and reduces $k_{\min }{ }^{\text {rc }}$ only slightly. 


\begin{tabular}{|c|c|c|c|c|c|c|c|c|}
\hline residue & $\begin{array}{c}k_{\mathrm{A}}{ }^{\mathrm{rc}} \\
\left(\mathrm{M}^{-1} \min ^{-1}\right)\end{array}$ & $\begin{array}{c}k_{\mathrm{A}}{ }^{\text {obs }} \\
\left(\mathrm{M}^{-1} \min ^{-1}\right)\end{array}$ & $\begin{array}{c}k_{\mathrm{B}}{ }^{\mathrm{rc}} \\
\left(\mathrm{M}^{-1} \min ^{-1}\right)\end{array}$ & $\begin{array}{c}k_{\mathrm{B}}{ }^{\text {obs }} \\
\left(\mathrm{M}^{-1} \min ^{-1}\right)\end{array}$ & $\begin{array}{c}k_{\min }{ }^{\mathrm{rc}} \\
\left(\min ^{-1}\right)\end{array}$ & $\begin{array}{c}k_{\min }{ }^{o b s} \\
\left(\min ^{-1}\right)\end{array}$ & $\mathrm{pD}_{\min }{ }^{\mathrm{rc}}$ & $\mathrm{pD}_{\min }{ }^{\mathrm{obs}}$ \\
\hline Aib-1 & 1269.6 & 1587.1 & $1.16 \times 10^{9}$ & $1.77 \times 10^{7}$ & 0.097 & $1.33 \times 10^{-2}$ & 4.42 & 5.38 \\
\hline Aib-3 & 46.1 & 46.6 & $1.46 \times 10^{9}$ & $4.34 \times 10^{5}$ & 0.025 & $3.58 \times 10^{-4}$ & 3.65 & 5.41 \\
\hline Ala-4 & 225.8 & 1.11 & $2.02 \times 10^{9}$ & $1.69 \times 10^{5}$ & 0.060 & $3.44 \times 10^{-5}$ & 3.92 & 4.81 \\
\hline Aib-5 & 71.4 & 1.25 & $2.55 \times 10^{9}$ & $2.67 \times 10^{5}$ & 0.042 & $4.59 \times 10^{-5}$ & 3.62 & 4.74 \\
\hline Ala-6 & 225.8 & 3.98 & $2.02 \times 10^{9}$ & $9.59 \times 10^{4}$ & 0.060 & $4.91 \times 10^{-5}$ & 3.92 & 5.21 \\
\hline Gln-7 & 24.8 & 2.43 & $2.55 \times 10^{10}$ & $1.11 \times 10^{6}$ & 0.141 & $1.30 \times 10^{-4}$ & 2.89 & 4.57 \\
\hline Aib-8 & 38.3 & 2.40 & $4.04 \times 10^{9}$ & $2.06 \times 10^{6}$ & 0.018 & $1.77 \times 10^{-4}$ & 3.39 & 4.43 \\
\hline Val-9 & 41.1 & 1.79 & $4.04 \times 10^{8}$ & $2.30 \times 10^{4}$ & 0.012 & $1.61 \times 10^{-5}$ & 3.90 & 5.35 \\
\hline Aib-10 & 35.8 & 0.84 & $1.85 \times 10^{9}$ & $1.65 \times 10^{5}$ & 0.021 & $2.96 \times 10^{-5}$ & 3.54 & 4.75 \\
\hline Gly-11 & 136.0 & 14.9 & $3.77 \times 10^{9}$ & $1.13 \times 10^{7}$ & 0.068 & $1.39 \times 10^{-3}$ & 3.68 & 4.46 \\
\hline Leu-12 & 32.6 & 0.92 & $8.62 \times 10^{9}$ & $1.36 \times 10^{5}$ & 0.068 & $2.82 \times 10^{-5}$ & 3.18 & 4.81 \\
\hline Aib-13 & 52.9 & 0.23 & $1.57 \times 10^{9}$ & $2.23 \times 10^{5}$ & 0.028 & $1.81 \times 10^{-5}$ & 3.66 & 4.41 \\
\hline Val-15 & 8.6 & 1.11 & $2.55 \times 10^{9}$ & $1.69 \times 10^{5}$ & 0.020 & $3.44 \times 10^{-5}$ & 3.16 & 4.81 \\
\hline Aib-16 & 35.8 & 1.22 & $1.85 \times 10^{9}$ & $3.34 \times 10^{4}$ & 0.026 & $1.60 \times 10^{-5}$ & 3.54 & 5.18 \\
\hline Aib-17 & 220.6 & 0.63 & $2.32 \times 10^{8}$ & $4.67 \times 10^{4}$ & 0.019 & $1.37 \times 10^{-5}$ & 4.39 & 4.96 \\
\hline Gln-18 & 76.5 & 1.79 & $2.32 \times 10^{6}$ & $1.61 \times 10^{5}$ & 0.041 & $6.00 \times 10^{-5}$ & 3.66 & 4.92 \\
\hline Gln-19 & 13.3 & 2.30 & $4.03 \times 10^{10}$ & $1.19 \times 10^{6}$ & 0.181 & $1.31 \times 10^{-4}$ & 2.66 & 4.54 \\
\hline Pho-20 & 11.9 & 114.3 & $2.02 \times 10^{10}$ & $1.24 \times 10^{5}$ & 0.146 & $3.00 \times 10^{-4}$ & 2.78 & 5.88 \\
\hline
\end{tabular}

${ }^{a}$ Note that the measured exchange data for Ala- 4 and Val-15 are given identical values because their cross peaks could not be resolved in any of the spectra.

Observed $H_{N}$ Exchange Rates in Alamethicin Dissolved in SDS Solution. Figure 3 shows examples of HMQC spectra acquired at different time intervals after an aliquot of alamethicin in $\mathrm{SDS}-\mathrm{H}_{2} \mathrm{O}$ solution was diluted with SDS$\mathrm{D}_{2} \mathrm{O}$ solution. The resolution in the ${ }^{15} \mathrm{~N}$ dimension is low because of the small number of $\mathrm{F}_{1}$ increments; however, the cross peaks of residues $1,3,6,11,12,13,16$, and 20 are completely free from overlap and provide reliable hydrogen exchange data which fit well to monoexponential decay curves, representatives of which are shown in Figure 4a. Although they overlap slightly, the cross peaks of residues 8 and 17 are well enough resolved to provide reliable hydrogen exchange data for each residue and to fit well to monoexponential decay curves. Note as well that Aib 8 exchanges much more rapidly than Aib 17 at several $\mathrm{pH}$ values providing data for the latter which is free of any overlap from the Aib 8 cross peak (see Figure 3 ). The cross peaks for the pairs of residues Ala 4/Val 15 and Val 9/Gln 18 are also well enough resolved to provide reliable hydrogen exchange data for the pairs of amides; however the pairs themselves are not separable in this experiment. The Ala 4/Val 15 cross peak decays were fit to single- and doubleexponential decays with little difference in the goodness of the fits. On the other hand, the Val 9/Gln 18 decays in the base-catalyzed exchange region fit significantly better to biexponential curves than to a monoexponential curve, suggesting that separation of the peaks can be achieved kinetically (see Figure 4b). The pairs of cross peaks Aib 5/Aib 10 and Gln 7/Gln 19 overlap significantly in the exchange experiments (Figure 3). Visual inspection of the spectra suggests that neither amide of the pair exchanges significantly faster than the other in either the acid- or the base-catalyzed regions. The decays of both pairs of cross peaks fit to single- and double-exponential curves with little difference in the goodness of the fits. This suggests that at most $\mathrm{pD}$ values, Aib 5 exchanges at about the same rate as Aib 10 and that Gln 7 exchanges at about the same rate as Gln 19.

To obtain residue-specific exchange data for the overlapping resonances, we acquired high-resolution $2 \mathrm{D}$ spectra at different time intervals after an aliquot of alamethicin in
$\mathrm{SDS}-\mathrm{H}_{2} \mathrm{O}$ solution was diluted with $\mathrm{SDS}-\mathrm{D}_{2} \mathrm{O}$ solution at $\mathrm{pD}_{\text {corr }} 6.0$ and 6.8. Figure 5 shows an HSQC spectrum obtained immediately upon dilution of the peptide, which indicates that all of the ${ }^{15} \mathrm{~N}^{1} \mathrm{H}$ cross peaks are resolved except for Ala 4/Val 15. In the absence of evidence that the amide hydrogens of these two residues exchange with different rates, we assume one rate for both (see Table 2). The highresolution spectra confirmed the biexponential analysis of the low-resolution cross peak decay of Val 9/Gln 18 and indicated that the decay of Gln-18 is nearly 10 -fold faster than that of Val 9 in the base-catalyzed limb of the exchange data (see Table 2). The high-resolution spectra also confirmed the conclusions from the low-resolution spectra that the rates of exchange for Aib 5 and Aib 10 are nearly identical in the base-catalyzed limb. Analysis of the decays of the Gln 7 and Gln 19 cross peaks indicates that Gln 7 exchanges at about the same rate as Gln 19 (see Table 2).

The $\mathrm{pD}$ dependence of HD exchange for 4 representative residues is plotted in Figure 6. The curves through the data are nonlinear least-squares fits weighted as described in Methods. The excellent fits of our data to eq 5 and the slopes near unity suggest that exchange occurs via the EX2 mechanism; that is, acid- and base-catalyzed exchange occurs from the open, non-H-bonded state and that the conformational closing rate $\left(k_{\mathrm{cl}}\right)$ is significantly greater than both the conformational opening rate $\left(k_{\mathrm{op}}\right)$ and the chemical exchange rate $(40,41)$. The acid- and base-catalyzed exchange rates, the $\mathrm{pD}_{\min }$, and $k_{\min }$ values are listed in Table 2 where they can be compared to the predicted exchange rates for an unstructured peptide. The predicted $\mathrm{pD}$ dependence of exchange for residues in an unstructured peptide is also indicated by dashed lines in Figure 6.

The measured exchange parameters for alamethicin in aqueous SDS can also be compared to the predicted rates of exchange in an unstructured peptide by calculating protection factors (PF) for $k_{\mathrm{A}}, k_{\mathrm{B}}$, and $k_{\min }$ (see Figure 7 ), defined as the ratio of the calculated rate of exchange in the unstructured molecule to the measured rate of exchange in the folded molecule. The inverse of the protection factor is a measure of the equilibrium constant for the $\mathrm{H}$-bond opening fluctuation $\left(K_{\mathrm{op}}=k_{\mathrm{op}} / k_{\mathrm{cl}}\right)$ in the EX2 mechanism where chemical 


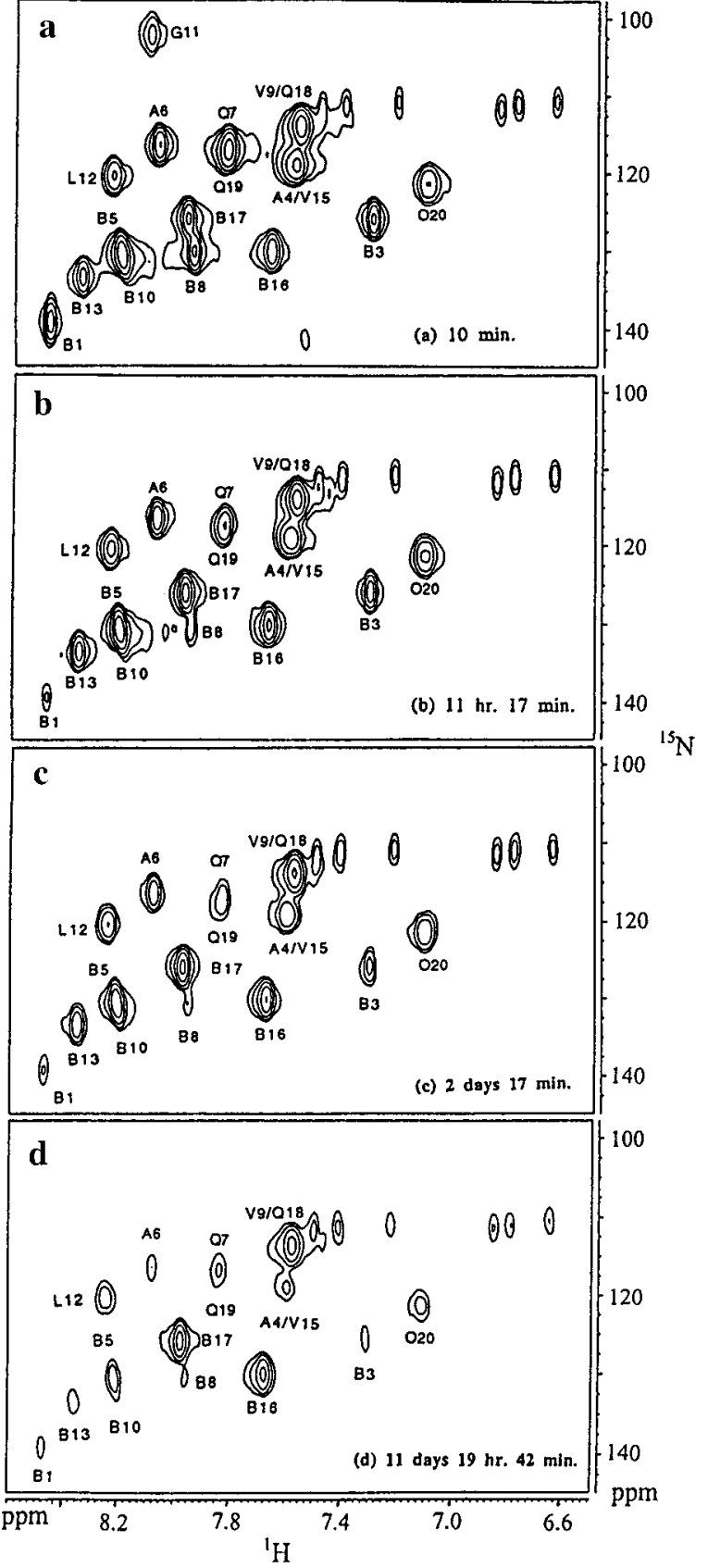

FIGURE 3: Representative HMQC spectra $(33,34)$ of ${ }^{15} \mathrm{~N}$-labeled alamethicin in $150 \mathrm{mM}$ SDS-D $25,20 \mathrm{mM} \mathrm{Na} 2 \mathrm{HPO}_{4}, \mathrm{pD}_{\text {corr }} 6.1$. Spectra were acquired (a) $10 \mathrm{~min}$, (b) $11 \mathrm{~h} 17 \mathrm{~min}$, (c) 2 days 17 min, and (d) 11 days $19 \mathrm{~h} 42$ min after the sample in $\mathrm{H}_{2} \mathrm{O}$ was diluted with $\mathrm{D}_{2} \mathrm{O}$. The number of scans was 32, and a total of 32 increments of 1024 data points each were acquired. Each experiment required 19 min $53 \mathrm{~s}$ to acquire. The $\mathrm{F}_{1}$ dimension was zero filled to 256 points, no zero filling was applied to the $F_{2}$ dimension, and a $\pi / 2$-shifted sine-squared filter was applied to both dimensions before Fourier transformation.

exchange is much slower than the closing rate $k_{\mathrm{cl}}$. With the exception of Aib-1, Aib-3, and Pho-20, the residues show depression of both the acid- and base-catalyzed exchange rates, with the base-catalyzed exchange experiencing a larger depression than the acid-catalyzed rates (see Figure 7a,b). The acid-catalyzed exchange in Aib-3 is the same as that expected for a random coil amide but the base-catalyzed rate is depressed. The acid-catalyzed exchange rates at Aib-1 and Pho-20 are enhanced, but the base-catalyzed exchange rates are depressed. The largest protection factors for acid-
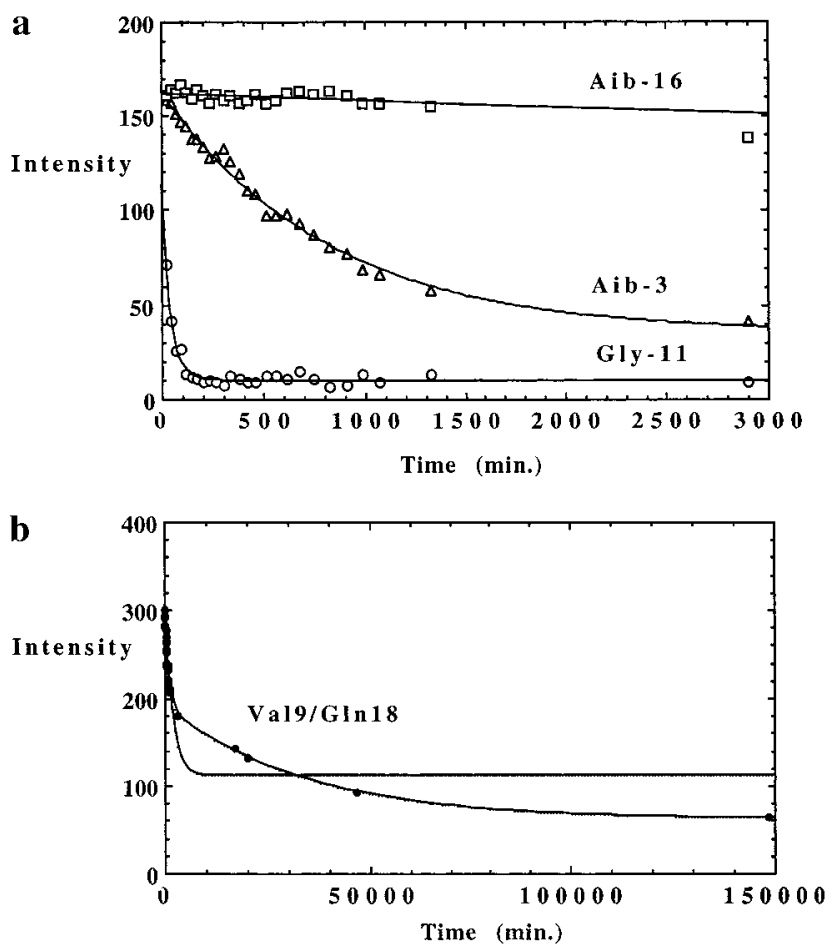

FIGURE 4: The change in representative HMQC cross-peak intensities of ${ }^{15} \mathrm{~N}$-labeled alamethicin in $150 \mathrm{mM}$ SDS-D $25,20 \mathrm{mM} \mathrm{Na}_{2}-$ $\mathrm{HPO}_{4}$ solution, $\mathrm{pD}_{\text {corr }} 6.1$ as a function of time. (a) Aib-3 $(\Delta)$, Gly11(O), and Aib-16 ( $\square$ ) HD exchange data fit to monoexponential decays; (b) Val 9/Gln 18 cross-peaks (৩) fit to a monoexponential decay and to a biexponential decay.

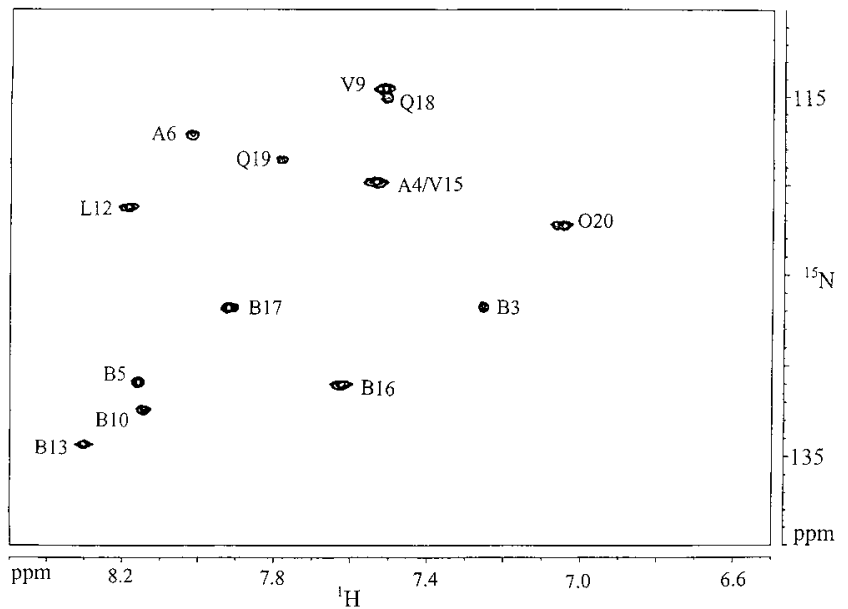

FIGURE 5: A high-resolution HSQC spectrum (35) of ${ }^{15} \mathrm{~N}$-labeled alamethicin in $150 \mathrm{mM}$ SDS-D $25,20 \mathrm{mM} \mathrm{Na}_{2} \mathrm{HPO}_{4}$ solution, $\mathrm{pD}_{\text {corr }}$ 6.8 acquired immediately after the sample in SDS $-\mathrm{H}_{2} \mathrm{O}$ was diluted with SDS $-\mathrm{D}_{2} \mathrm{O}$. The number of scans was 32. A total of 512 increments of 1024 data points each were acquired. The $F_{1}$ dimension was zero filled to 1000 points, the $F_{2}$ dimension was zero filled to 4000 , and a $\pi / 2$-shifted sine-squared filter was applied to both dimensions before Fourier transformation.

catalyzed exchange are for Ala-4, Aib-13, and Aib-17 at 200-400. The rest have protection factors from 10 to 50 . The base-catalyzed protection factors are much larger than the acid-catalyzed protection factors. The smallest calculated value is for Aib-1 followed by Gly-11 which has a protection factor of 334; Aib-8 has a protection factor on the order of 1000; Leu-12, Aib-16, and Pho-20 have protection factors on the order of $10^{5}$; and the rest are on the order of $10^{4}$. This is the opposite to what occurs in methanol where the 

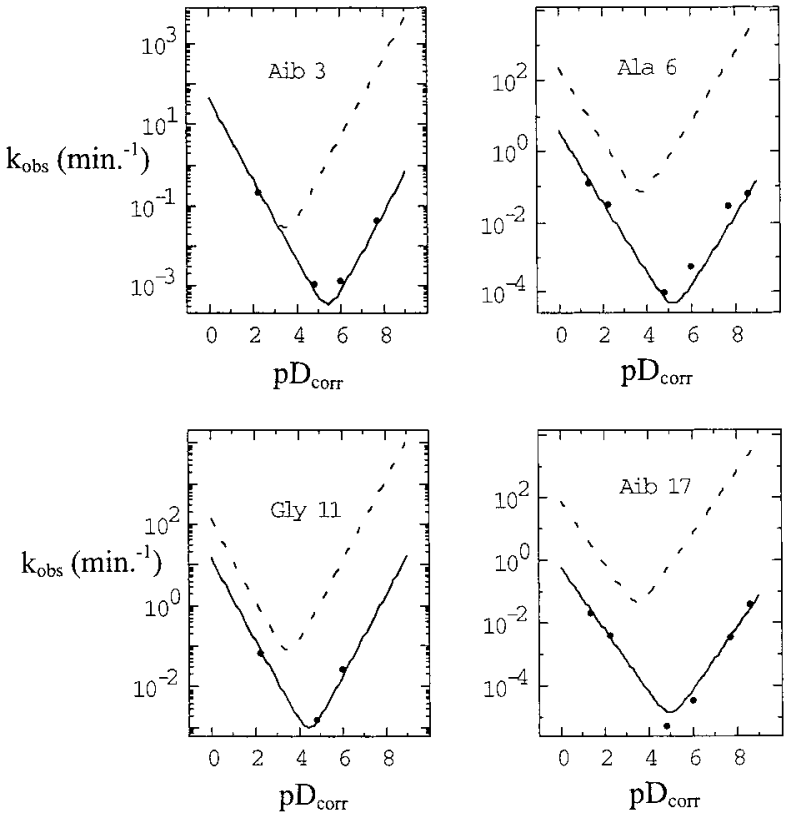

FIGURE 6: The dependence of $\mathrm{HD}$ exchange rates on $\mathrm{pD}_{\text {corr }}$ of representative $\mathrm{H}_{\mathrm{N}}$ in alamethicin in $20 \mathrm{mM} \mathrm{Na} \mathrm{HPO}_{4}, 150 \mathrm{mM}$ SDS- $\mathrm{D}_{25}$ solution. The solid curves are the best fits of the data to eq 5 , and the dashed curves are the predicted exchange rates for the $\mathrm{H}_{\mathrm{N}}$ of alamethicin in a hypothetical unfolded molecule. The predicted exchange rates were calculated following the methods in ref 30 .

acid-catalyzed rates are generally more depressed than the base-catalyzed rates $(21)$. Figure $7 \mathrm{c}$ shows that the smallest protection factor at the $\mathrm{pD}_{\min }\left(\mathrm{PF} k_{\min }\right)$ is observed at Aib-1, followed by Gly-11, Aib-3, and Aib-8. The largest observed is for Leu-12 which is 2400 .

\section{DISCUSSION}

Proper interpretation of the hydrogen exchange rates measured for alamethicin dissolved with aqueous detergent requires a separation of the effects of $\mathrm{H}$-bonding (peptide conformational stability) from the effects of detergent on each of the exchange parameters. Studies on model compounds (42), alanine-based helical peptides (24), and proteins (22) suggest that local unfolding of at least one peptide unit with $\mathrm{H}$-bond breaking at both the $\mathrm{NH}$ and $\mathrm{CO}$ precedes acid- and base-catalyzed hydrogen exchange in secondary amides. The effect of $\mathrm{H}$-bonding is to depress $k_{\mathrm{A}}$ and $k_{\mathrm{B}}$ equally, depressing $k_{\min }$ but leaving the $\mathrm{pD}_{\min }$ the same as in model compounds. SDS has the opposite effect on HD exchange. Studies on small peptides (43) and model compounds (27) suggest that the negative electrostatic surface of SDS micelles elevates the local proton concentration and diminishes the hydroxide concentration effectively lowering the $\mathrm{pH}$ near the micelle. The difference between the measured bulk $\mathrm{pH}$ and the local $\mathrm{pH}$ causes an apparent enhancement of $k_{\mathrm{A}}$ and a depression of $k_{\mathrm{B}}$ which are equal, resulting in an elevated $\mathrm{pD}_{\text {min }}$ and an unchanged $k_{\min }$ (27). Application of these conclusions from the small molecule research to SDSsolubilized alamethicin suggests that intramolecular $\mathrm{H}$ bonding can be monitored through the parameter $k_{\min }$ and that interactions with detergent are revealed by the parameter $\mathrm{pD}_{\min }$. Exceptions to these generalizations are possible and are discussed below.
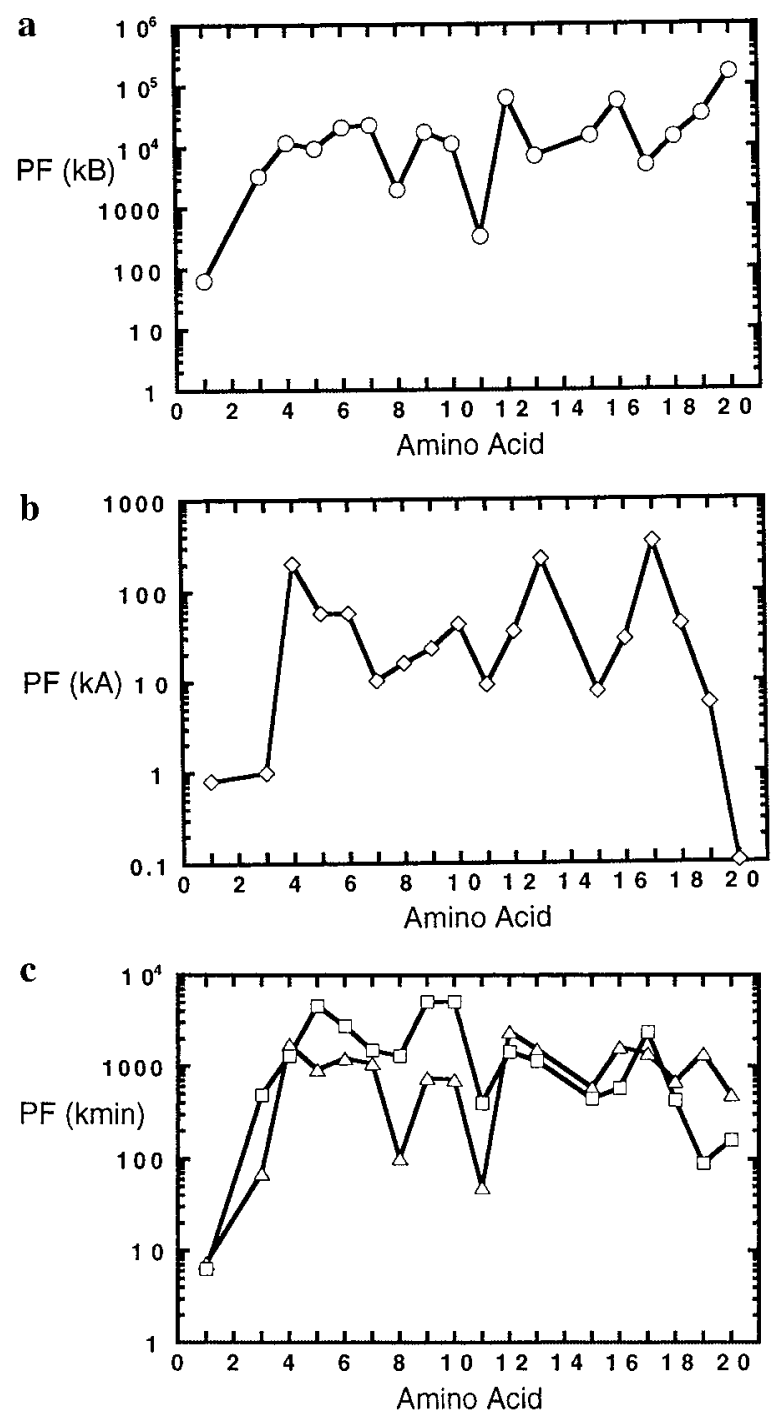

FIGURE 7: Sequence-dependent protection factors $k_{\mathrm{B}}(\bigcirc), k_{\mathrm{A}}(\diamond)$, and $k_{\min }(\Delta)$, for alamethicin dissolved in SDS were calculated by dividing the rates of HD exchange calculated for an unstructured peptide by those observed in alamethicin and listed in Table 2. The $\operatorname{PF}\left(k_{\min }\right)$ values for alamethicin dissolved in methanol ( $\left.\square\right)$ were taken from Dempsey (21).

Conformational Stability of the Alamethicin Backbone. Figure $7 \mathrm{c}$ compares the sequence-dependent retardation of HD exchange in alamethicin dissolved in aqueous detergent with that for alamethicin dissolved in methanol as determined by Dempsey (21). Both sets of data have been corrected for sequence-dependent inductive and steric effects using similar, though not identical, reference compounds. The protection factors for methanol were calculated from the measured $k_{\text {min }}$ for alamethicin and exchange data for model dipeptides dissolved in methanol (21). The protection factors for detergent were calculated from the measured $k_{\min }$ for alamethicin dissolved in detergent and exchange data for poly D,Lalanine dissolved in water (30). The difference in the rates of exchange of the reference molecules is approximately 2-fold, resulting in a slight inflation of the PFs for the peptide dissolved in methanol compared to those in detergent. The similarity in the $\mathrm{PF}\left(k_{\mathrm{min}}\right)$ values for all residues in alamethicin in the two solvents (Figure 7c) is striking and suggests that the conformational stability of the backbone is identical in the two most common solvents used for its study. This is 
most likely due to the high helix propensity of the Aib residue due to the steric interactions of the additional $\alpha$-methyl group (44) which limits the influence of solvent on conformation. Note that comparison of protection factors at the $k_{\min }$ has the advantage of eliminating sequence-dependent inductive and steric effects, the significant differences in exchange due to different catalyst concentrations in methanol and water, and the possible effects of differences in $\mathrm{pD}$ measurements in the two solvent systems.

The $\operatorname{PF}\left(k_{\min }\right)$ values indicate that the alamethicin backbone in methanol and SDS is significantly more stable than the backbones of other peptides of similar size dissolved in water. Rates of exchange at the $\mathrm{pD}_{\min }$ of a 21-residue Ala-based helical peptide $\left(N\right.$-Ac- $\left.[\mathrm{AAKAA}]_{4}-\mathrm{Y}-\mathrm{NH}_{2}\right)$ are retarded by up to 8-fold compared to PDLA (24). Thus, exchange from the stable core of the Ala-based peptide is more than 100 times faster than that from the core of alamethicin. The termini of alamethicin are also much more resistant to exchange than are the ends of Ala-based peptides which are often described as dynamically frayed (24). In alamethicin, exchange at residue 1 is slowed by a factor of about 8 compared to a freely exchanging amide. Since neither an $\alpha$ nor a 310 -helical conformation could provide an intramolecular carbonyl for H-bonding to the Aib-1 NH, the slow exchange must reflect a stable steric interaction at the $\mathrm{N}$-terminus, present in the peptide in both solvents $(21,27)$. The stability of the conformation at the N-terminus is also indicated by the slow exchange at residue 3 most likely reflecting a H-bond between the terminal acetyl and the Aib-3 $\mathrm{NH}$ (12).

Compared to the rest of the core of the peptide, amide exchange at Gly-11 is relatively rapid, although it is certainly much more resistant to exchange than all of the residues in the Ala-based peptide. The rapid exchange at Gly-11 suggests a highly local conformational flexibility in the middle of the peptide on the millisecond to submicrosecond time scale. By comparison, substitution of a central Ala residue by a Gly in a 20 residue Ala-based peptide results in a global destabilization of the helix and a reduction of the fractional helix content from $90 \%$ to $20 \%$ (45). Interestingly, increased local flexibility is not observed on the picosecond to nanosecond time scale in NMR relaxation experiments for alamethicin dissolved in either methanol or SDS (18). Recently, molecular dynamics simulations of alamethicin in the presence of methanol confirmed the general stability of the backbone hydrogen bonds throughout the peptide (15). Increased flexibility was observed about the dihedral angles $\Psi$ of Aib-10, $\Phi$ and $\Psi$ of Gly-11, and $\Phi$ of Leu-12 indicating the extent of the helix disruption caused by the central Gly residue. Flexibility at Gly-11 might be important in the mechanism by which the peptide, initially adsorbed onto a membrane surface, begins to penetrate the bilayer or it might be involved in mediating the conformational changes involved in changing the pores between the open and closed states.

A Model for Alamethicin Interaction with Anionic Lipid. The $\mathrm{pD}_{\min }$ values for alamethicin dissolved in detergent are mostly 1-2 pD units higher than those calculated for an unstructured molecule dissolved in water (see Table 2). This is likely due to the negatively charged surface of the micelle which causes an apparent enhancement of acid-catalyzed exchange and a depression of base-catalyzed exchange and

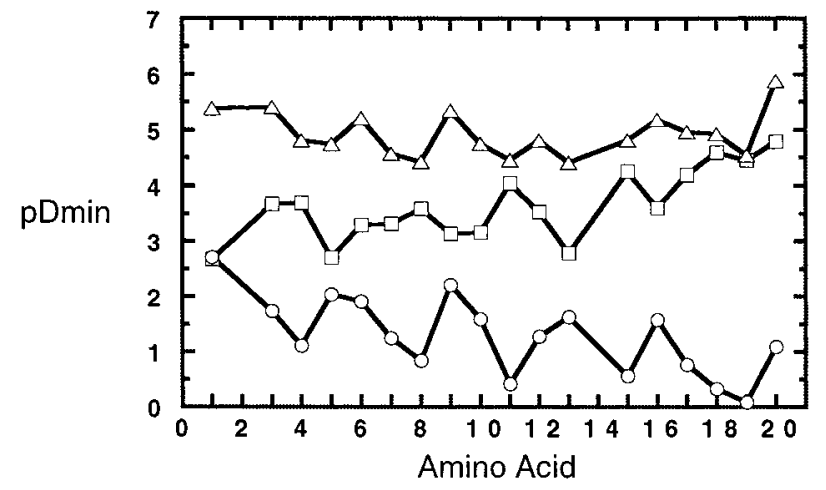

FIGURE 8: The difference data $(O)$ were calculated by subtracting the $\mathrm{pD}_{\min }$ values measured for alamethicin dissolved in aqueous $\operatorname{SDS}(\triangle)$ from the $\mathrm{pD}_{\min }$ values measured for alamethicin dissolved in methanol ( $\square$ ) as reported by Dempsey (21).

has been observed in studies with several model compounds thought to interact primarily with the surface of the micelle $(27,43)$. This electrostatic effect on exchange indicates that exchange occurs from the peptide in association with the detergent micelle. This is in contrast to the H:D exchange measurements of alamethicin in the presence of lipid (25). Those results suggested that in some circumstances exchange occurred only after the peptide had dissociated from the membrane and was in a water-soluble state. The $\mathrm{pD}_{\min }$ values measured in detergent are also significantly higher than those measured for the peptide dissolved in methanol (21) as shown in Figure 8. As discussed above, comparison of these values is complex in part due to the difficulty of measuring $\mathrm{pD}$ in methanol. However, analysis of the model compound exchange data (see Results) suggests that the $\mathrm{pD}$ values reported for methanol may be slightly high so that correction for this effect would only magnify the differences in $\mathrm{pD}_{\text {min }}$ measured in the two solvents. Figure 8 shows that the $\mathrm{pD}_{\min }$ values in SDS appear to fluctuate about a mean value of 4.9, whereas the values in methanol are lowest at the $\mathrm{N}$-terminus and increase to their highest values at the C-terminus (21). The latter observation was ascribed to the direct effect of a helical macrodipole on hydrogen exchange at the termini of the peptide (21), and the effects of an alamethicin macrodipole on amide proton chemical shift in methanol have been discussed previously (12). The resistance to HD exchange of the entire backbone of alamethicin dissolved in SDS suggests that the helix in SDS is as stable as that present in methanol (Figure 7c) but that the effect of the macrodipole on HD exchange is masked by the negative electrostatic charge on the surface of the micelle. Assuming that the conformation of the peptide and the magnitude of the macrodipole are similar in the two solvents, the differences in $\mathrm{pD}_{\min }$ in methanol and SDS should reveal the net effect of the detergent on the $\mathrm{pD}_{\min }$ values. The difference data, shown in Figure 8, are larger at the N-terminus and decrease as the $\mathrm{C}$-terminus is approached. This suggests that the positive end of the macrodipole at the $\mathrm{N}$-terminus of alamethicin interacts more strongly with the negatively charged surface of an SDS micelle than does the C-terminus where the negative end of the dipole resides.

The difference $\mathrm{pD}_{\min }$ data also reveal a periodicity (Figure 8) not readily apparent in the original data but which suggests that one surface of the helix interacts more strongly with the micelle. On the basis of the positions of the peaks in the 
difference data, that surface consists of residues $1,5,9,13$, 16 , and 20 whose $\mathrm{pD}_{\min }$ are most strongly perturbed by the detergent. This definition of one face of the helix is nearly identical to one generated by molecular dynamics simulations of the peptide solvated by methanol (Figure 2C; ref 15). The conformation is predominantly $\alpha$-helical but also includes $3_{10}$ interactions involving the NHs of Aib-3, Ala-4, Val-9, Val-15, and Gln-18. The conformation is bent, due to a rotation of the Aib-10-Gly-11 peptide and the presence of proline at position 14 , and the concave surface of the helix is similar to that described by the $\mathrm{pD}_{\min }$ difference data in Figure 8 . The opposite face of the helix $(4,7,11,15,19)$ contains several polar residues (Gln-7, Gly-11, Gln-19) and some of the least perturbed $\mathrm{pD}_{\min }$ values suggesting that, on average, this side of the helix faces solvent.

Many membrane-active peptides such as the antibiotic magainins, cecropins, and melittin (4), mitochondrial import signal sequences, and transmembrane protein segments (46) are thought to interact with membranes through a combination of hydrophobic and electrostatic interactions. Electrostatic interactions may dominate the initial stages of peptidemembrane interaction as an unfolded, amphipathic, cationic peptide interacts with anionic lipid headgroups at the membrane surface. Hydrophobic interactions then drive amphipathic helix formation and partial penetration of the peptide into the bilayer in a topology in which the nonpolar face of the helix interacts with lipid hydrocarbon and the cationic surface faces solvent and anionic heads (4). This can then be followed by transient insertion of the peptide across the bilayer which may be stabilized by peptidepeptide interactions. Our results suggest that alamethicin could interact with anionic lipid through the cationic amino terminus of its preformed helical macrodipole. Similar to its interaction with an anionic micelle, the peptide would maximize electrostatic interactions with the anionic lipid heads and burial of its hydrophobic groups. These results illustrate the key role of the Aib residue in assisting a neutral peptide to interact with a membrane. The high helix propensity of the Aib residue drives helix formation and, through the macrodipole, allows the peptide to interact electrostatically with the membrane. The observation that some alamethicin isomers contain a single glutamic acid residue near the $\mathrm{C}$-terminus suggests that alamethicin may also be able to interact with cationic lipid using the glutamic acid or the anionic end of the macrodipole.

Hydrogen Exchange-Enabling Conformational Changes. The preceding analyses were based on the assumption that acid- and base-catalyzed hydrogen exchange is enabled by local unfolding events which expose the amide and the carbonyl units of each peptide to solvent catalysts. It is possible, however, that base-catalyzed exchange occurs via small-amplitude fluctuations at the nitrogen, whereas acidcatalyzed exchange requires larger conformational fluctuations which expose the entire peptide bond (imidic acid mechanism) $(42,47)$. For such residues base catalysis would be enhanced compared to acid catalysis and the asymmetry in the molecular dynamics would lower the $\mathrm{pD}_{\min }$ complicating the analysis. Just such a separation of conformational events for acid- and base-catalyzed exchange was necessary to explain the rapid exchange at the two amino-terminal residues in a 21-residue Ala-based peptide which are not $\mathrm{H}$-bonded but was not required for the rest of the residues
$(24,48)$. In alamethicin, exchange of the non-hydrogenbonded Aib-1 NH is retarded and the $\mathrm{pD}_{\min }$ is among the highest measured in alamethicin, so it is not necessary to invoke different conformational events for exchange catalyzed by acid and base.

Although EX2 hydrogen exchange gives no direct information about the structural fluctuations enabling exchange, nanosecond molecular dynamics simulations may provide some clues. Simulations of alamethicin (15) show that largeamplitude fluctuations in conformation occur at the $\Psi$ dihedral bond angle of Aib-10, the $\Phi$ and $\Psi$ angles of Gly11, and the $\Phi$ angle of Leu-12. If correlated fluctuations about the $\Psi$ and $\Phi$ angles adjacent to a peptide unit were sufficient to permit exchange, we would expect rapid exchange at the NH of residues Gly-11 and Leu-12, whereas exchange at Gly-11 is much faster than at Leu-12 (Figure 7c). This suggests that exchange at Gly-11 is facilitated by conformational fluctuations involving at least three and perhaps four sequential dihedral bond angles as occurs in cooperative helix-coil transitions (24). The slow exchange at the other residues in alamethicin suggests that hydrogen exchange reports rare cooperative events in which several consecutive H-bonds are broken, as occurs, for example, in the unwinding of one turn of helix.

\section{ACKNOWLEDGMENT}

We thank Dr. Kirk Marat and Mr. Terry Wolowiec for maintenance of the NMR spectrometer and a reviewer for helpful comments.

\section{REFERENCES}

1. Deber, C. M., and Goto, N. K. (1996) Nat. Struct. Biol. 3, 815-818.

2. Sansom, M. S. P. (1993) Q. Rev. Biophys. 26, 365-421.

3. Cafiso, D. S. (1994) Annu. Rev. Biophys. Biomol. Struct. 23, $141-165$.

4. Bechinger, B. (1997) J. Membr. Biol. 156, 197-211.

5. Wu, Y., He, K., Ludtke, S. J., and Huang, H. W. (1995) Biophys. J. 68, 2361-2369.

6. He, K., Ludtke, S. J., Huang, H. W., and Worcester, D. L. (1995) Biochemistry 34, 15614-15618.

7. He, K., Ludtke, S. J., Worcester, D. L., and Huang, H. W. (1996) Biophys. J. 70, 2659-2666.

8. You, S., Peng, S., Lien, L., Breed, J., Sansom, M. S. P., and Woolley, G. A. (1996) Biochemistry 35, 6225-6232.

9. Fox, R. O., and Richards, F. M. (1982) Nature 300, 325330.

10. Esposito, G., Carver, J. A., Boyd, J., and Campbell, I. D. (1987) Biochemistry 26, 1043-1050.

11. Yee, A. A., and O'Neil, J. D. J. (1992) Biochemistry 31, 31353143.

12. Yee, A. A., Babiuk, R. P., and O'Neil, J. D. J. (1995) Biopolymers 36, 781-792.

13. Franklin, J. C., Ellena, J. F., Jayasinghe, S., Kelsh, L. P., and Cafiso, D. S. (1994) Biochemistry 33, 4036-4045.

14. Fraternali, F. (1990) Biopolymers 30, 1083-1099.

15. Gibbs, N., Sessions, R. B., Williams, P. B., and Dempsey, C. E. (1997) Biophys. J. 72, 2490-2495.

16. North, C. L., Franklin, J. C., Bryant, R. G., and Cafiso, D. S. (1994) Biophys. J. 67, 1861-1866.

17. Kelsh, L. P., Ellena, J. F., and Cafiso, D. S. (1992) Biochemistry 31, 5136-5144.

18. Spyracopoulos, L., Yee, A., and O’Neil, J. D. J. (1996) J. Biomol. NMR 7, 283-294.

19. Arkawa, T., and Goddette, D. (1985) Arch. Biochem. Biophys. 240, 21-32.

20. Yee, A. A., Marat, K., and O’Neil, J. D. J. (1997) Eur. J. Biochem. 243, 283-291.

21. Dempsey, C. E. (1995) J. Am. Chem. Soc. 117, 7526-7534. 
22. Englander, S. W., and Kallenbach, N. R. (1984) Q. Rev. Biophys. 16, 521-655.

23. Englander, S. W., and Mayne, L. (1992) Annu. Rev. Biophys. Biomol. Struct. 21, 243-265.

24. Rohl, C. A., and Baldwin, R. L. (1994) Biochemistry 33, 7760-7767.

25. Dempsey, C. E., and Handcock, L. J. (1996) Biophys. J. 70, 1777-1788.

26. Boheim, G., Hanke, W., and Jung, G. (1983) Biophys. Struct. Mech. 9, 181-191.

27. Spyracopoulos, L., and O'Neil, J. D. J. (1994) J. Am. Chem. Soc. 116, 1395-1402.

28. Levy, G. C., and Lichter, R. L. (1979) Nitrogen-15 Nuclear Magnetic Resonance Spectroscopy, John-Wiley and Sons, New York.

29. Means, G. E., and Feeney, R. E. (1971) Chemical Modification of Proteins, Holden-Day, Inc., Toronto.

30. Bai, Y., Milne, J. S., Mayne, L., and Englander, S. W. (1993) Proteins: Struct., Funct., Genet. 17, 75-86.

31. Glasoe, P., and Long, F. (1960) J. Phys. Chem. 64, 188-190.

32. Weast, R. C., Ed. (1987) CRC Handbook of Chemistry and Physics, 1st Student Ed., D103-D104, CRC Press, Florida.

33. Bax, A., Griffey, R. H., and Hawkins, B. L. (1983) J. Am. Chem. Soc. 105, 7188-7190.

34. Bax, A, Griffey, R. H., and Hawkins, B. L. (1983) J. Magn. Reson. 55, 301-315.
35. Bodenhausen, G., and Ruben, O. J. (1980) Chem. Phys. Lett. 69, 185-189.

36. Robertson, A. D., and Baldwin, R. L. (1991) Biochemistry 30, 9907-9914.

37. Molday, R. S., Englander, S. W., and Kallen, R. G. (1972) Biochemistry 11, 150-158.

38. Dempsey, C. E. (1988) Biochemistry 27, 6893-6901.

39. Augsperger, J. D., Bindra, V. A., Scheraga, H. A., and Kuki, A. (1995) Biochemistry 34, 2566-2576.

40. Hvidt, A. (1964) C. R. Trav. Lab. Carlsberg 34, 299-317.

41. Hvidt, A., and Nielson, S. O. (1966) Adv. Protein Chem. 21, 287-386.

42. Perrin, C. L., and Lollo, C. P. (1984) J. Am. Chem. Soc. 106, 2754-2757.

43. O'Neil, J. D. J., and Sykes, B. D. (1989) Biochemistry 28, 699-707.

44. Basu, G., and Kuki, A. (1993) Biopolymers 33, 995-1000.

45. Chakrabartty, A., Schellman, J. A., and Baldwin, R. L. (1991) Nature 351, 586-588.

46. Liu, L.-P., and Deber, C. M. (1997) Biochemistry 36, 54765482.

47. Fersht, A. R. (1971) J. Am. Chem. Soc. 93, 3504-3515.

48. Rohl, C. A., Scholtz, J. M., York, E. J., Stewart, J. M., and Baldwin, R. L. (1992) Biochemistry 31, 1263-1269.

BI982959T 